\title{
Mobile Devices for Early Literacy Intervention and Research with Global Reach
}

\author{
Cynthia \\ Breazeal \\ MIT \\ Cambridge, MA \\ cynthiab@media. \\ mit.edu
}

\author{
Robin Morris \\ Georgia State \\ University \\ Atlanta, GA \\ robinmorris \\ @gsu.edu
}

\author{
Stephanie \\ Gottwald \\ Tufts University \\ Medford, MA \\ steph.gottwald@ \\ tufts.edu
}

\author{
Tinsley \\ Galyean \\ Curious Learning \\ Cambridge, MA \\ tgalyean@curiou \\ slearning.org
}

\author{
Maryanne \\ Wolf \\ Tufts University \\ Medford, MA \\ maryanne.wolf@ \\ tufts.edu
}

\begin{abstract}
Extensive work focuses on the uses of technology at scale for post-literate populations (e.g., MOOC, learning games, Learning Management Systems). Little attention is afforded to non-literate populations, particularly in the developing world. This paper presents an approach using mobile devices with the ultimate goal to reach 770 million people. We developed a novel platform with a cloud backend to deliver educational content to over a thousand marginalized children in different countries: specifically, in remote villages without schools, urban slums with overcrowded schools, and at-risk, rural schools. Here we describe the theoretical basis of our system and results from case studies in three educational contexts. This model will help researchers and designers understand how mobile devices can help children acquire basic skills and aid each other's learning when the benefit of teachers is limited or nonexistent.
\end{abstract}

\section{Author Keywords}

Open platform for education; early literacy; reading brain; virtual preschool; pre-k learning and technology; global literacy project

\section{ACM Classification Keywords}

K.3.1. Computers and Education: Computer Use in Education.

\section{INTRODUCTION}

Never has full literacy been more important to a child's future, or more possible, due to unprecedented access to knowledge and the ubiquity of low cost mobile devices. Access, however, requires literacy. The reality is that over

Permission to make digital or hard copies of all or part of this work for personal or classroom use is granted without fee provided that copies are not made or distributed for profit or commercial advantage and that copies bear this notice and the full citation on the first page. Copyrights for components of this work owned by others than ACM must be honored. Abstracting with credit is permitted. To copy otherwise, or republish, to post on servers or to redistribute to lists, requires prior specific permission and/or a fee. Request permissions from Permissions@acm.org.

L@S 2016, April 25-26, 2016, Edinburgh, Scotland Uk

(C) 2016 ACM. ISBN 978-1-4503-3726-7/16/04 ..\$15.00

DOI: http://dx.doi.org/10.1145/2876034.2876046
57 million children have no school and will never become literate. Another 100 million attend such inadequate schools that they will remain functionally non-literate. Environmental degradation and increased refugees will swell that figure. Further, universal attendance in brickand-mortar schools will not be reached until 2050, and global teacher shortages are expected to worsen [12]. Alternative approaches must be explored.

Mobile devices offer the potential for providing educational content to children in multiple settings [9], but little comprehensive data exists on their efficacy [2]. This paper describes the design, deployment and early impact of an open platform for conducting global education research at scale and to collect data about engagement and learning. First, we describe a novel open platform that addresses the deployment and learning challenges faced by underresourced communities, particularly their limited access to literacy instruction. This platform is presently deployed in Ethiopia, Uganda, India, South Africa and rural United States and serves 1000 children (see Figure 1). The second innovative aspect involves 1) content curation grounded in principles from cognitive neuroscience about the reading brain; and 2) an educational strategy informed by

principles of social constructivist learning. Finally, we present results from three pioneering studies, each of
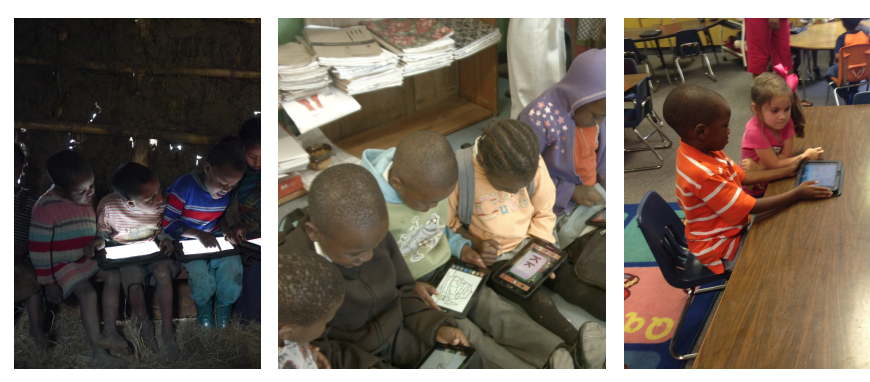

Figure 1: Children at our deployment sites using the tablets together. From left to right, in a remote Ethiopian village, in a school in South Africa and in a preschool in Alabama. 
which represents an under resourced community: 1) children with no access to schools in Ethiopia; 2) children in schools with 50 to 100:1 student- teacher ratio in South

Africa; and 3) an at-risk, underserved community in the United States. Each study follows controlled designs that

\begin{tabular}{|c|c|c|}
\hline Scenario & Deployment & Description \\
\hline $\begin{array}{l}\text { Disconnected- } \\
\text { Remote Tablet } \\
\text { Groups }\end{array}$ & e.g., Ethiopia & $\begin{array}{l}\text { No or very } \\
\text { infrequent Internet } \\
\text { connectivity on } \\
\text { site. Data stored on } \\
\text { tablets (e.g, SD } \\
\text { card). Manual } \\
\text { intervention for } \\
\text { data collection is } \\
\text { required, } \\
\text { aggregating the } \\
\text { data at a central, } \\
\text { better-connected } \\
\text { workstation, and } \\
\text { then uploading the } \\
\text { data to the server. }\end{array}$ \\
\hline $\begin{array}{c}\text { Directly- } \\
\text { Connected } \\
\text { Remote Tablet } \\
\text { Group }\end{array}$ & $\begin{array}{l}\text { e.g., USA } \\
\text { schools }\end{array}$ & $\begin{array}{l}\text { WiFi or cellular } \\
\text { connectivity to } \\
\text { regularly contacted } \\
\text { central server to } \\
\text { upload data and } \\
\text { receive updates. } \\
\text { Frequency of } \\
\text { uploads can be } \\
\text { throttled. }\end{array}$ \\
\hline $\begin{array}{c}\text { Indirectly- } \\
\text { Connected } \\
\text { Remote Tablet } \\
\text { Group }\end{array}$ & $\begin{array}{l}\text { e.g., South } \\
\text { Africa, school- } \\
\text { home use, etc. }\end{array}$ & $\begin{array}{c}\text { Strong, but } \\
\text { intermittent Wi-Fi } \\
\text { or cellular } \\
\text { connectivity. } \\
\text { Tablets make high- } \\
\text { speed connection to } \\
\text { local server cache, } \\
\text { which trickles data } \\
\text { to center server } \\
\text { through more } \\
\text { stable connection. } \\
\text { Meant for } \\
\text { deployment } \\
\text { protocols in which } \\
\text { tablets to return to } \\
\text { central location for } \\
\text { charging and data } \\
\text { uplink. }\end{array}$ \\
\hline
\end{tabular}

Table 1: The platform currently supports three kinds of deployment scenarios address the challenges of conducting rigorous study in these communities. Our cumulative work indicates the potential of this approach to continue to scale successfully to serve under-resourced communities around the world.

\section{PLATFORM}

Our technology design goals are 1) to monitor devices remotely; 2) to adjust educational content for learners and populations over time and with varied needs (see Table 1); and, 3 ) to deploy in conditions where Internet connection is difficult. Thus, our system is designed to:

- Work without an Internet connection by buffering data and providing alternate transmission paths.

- Support remote administration including the ability to monitor device health and remotely update content.

- Simplify maintenance and administration to support technical and non-technical local support personnel.

- Provide a path to scalability of a large number of sites and tablets.

- Limit usage to educational content, thus making it more accessible to a pre-literate population as well as reducing risk of theft.

The overall architecture is agnostic of any particular mobile device. This implementation uses android tablets because of: 1) the accessibility of the open source operating system; 2 ) affordability; and 3 ) availability to our populations. The current price (under \$70) provides economic incentives, compared to traditional costs of education. Note that in developing countries an average of $\$ 100 \mathrm{USD} /$ year is spent on education, compared to $\$ 10,000 \mathrm{USD} /$ year in the USA $[8 ; 11]$. This intervention can be delivered for far less, with continuous efficacy data. Further, the number of smartphones in developing countries is projected to be 1.4 billion by 2018 [5], that points to how quickly scalability could occur.

\section{Data Collection}

There are three types of usage data collected: 1) device health (e.g., battery level, accelerometer data, etc.); 2) educational apps (e.g., app launches, time used); and, 3) specific response data within apps (e.g., words touched, performance, repetitions of activities). This system is based on the Funf Open Sensing Framework [1] that runs on Android devices without user intervention. It consists of software on both the mobile device side, that collects and stores the data, transporting it when an Internet connection allows; and the server side, that processes and analyzes the data [3].

\section{Administrative Tools}

An administrative web interface helps to monitor device health and organize tablet information online. It also allows for web-based remote commands to be sent to tablets (e.g., updated content) while they are in the field. This essential component allows us to iterate rapidly to improve the intervention and the learners' experience. 


\section{STUDY OBJECTIVES}

The four major challenges faced by children with no or marginal schools were the basis for intervention objectives:

- Technological familiarity. To benefit from this intervention, children need sufficient familiarity with the tablets and to acquire a basic level of computer literacy, based largely on innate curiosity with no direct instruction.

- Basic conceptual knowledge and vocabulary. To benefit from the apps available, children need to understand basic concepts and vocabulary.

- Early literacy skills. To acquire basic literacy, children need exposure to precursor skills at the pre-k and first grade level (e.g., letter recognition, sight word reading, writing letters).

- Engagement and behavior. To sustain engagement, usage and literacy assessment data was used to update content.

\section{LITERACY INTERVENTION}

Our approach for tablet content design marries wellestablished theoretical cognitive neuroscience principles for how the young brain learns to read $[13 ; 14]$ with social constructionist principles of how children learn with others $[4,15]$, even in minimally invasive education environments [10].

\section{Tablet Content}

Reading is not natural to humans. It involves creating a new circuit in the brain by connecting linguistic, visual, cognitive and affective regions. These regions are responsible for the phonological, orthographic, semantic, and comprehension processes necessary for fluent reading to develop. Theoretically curated and designed apps were chosen or designed to develop children's three critical precursor skills: alphabetic knowledge [13; 14], vocabulary knowledge, and letter-sound correspondence rules. Additional apps were then chosen to introduce the next, early reading skills of blending and decoding using basic vocabulary words. Complimentary e-books and videos reinforce print knowledge, vocabulary, and new concepts. The resulting collection of over 70 apps in English includes multi-level interactive games, e-books, videos and creativity apps (e.g., drawing, music) that foster the developing reading circuit, the discovery of new types of learning, maintaining engagement, and better understanding of others.

\section{Tablet Exposure}

Social constructivist models of learning emphasize curiosity-driven exploration, collaboration among learners, and the ability of each child to construct meaning from well-designed content and interaction with peers. Studies in minimally invasive education environments show the key role that social learning context plays in promoting learning $[16,17]$. Children

\begin{tabular}{|c|c|}
\hline Method & Site \\
\hline $\begin{array}{l}\text { Receptive Vocabulary } \\
\text { 1. Peabody Picture Vocabulary } \\
\text { Test (PPVT-4) [6]; Children hear } \\
\text { a word; see four pictures; and are } \\
\text { asked which picture matches the } \\
\text { word. } \\
\text { 2. PPVT-4 adapted measure; } \\
\text { Specific to conceptual vocabulary } \\
\text { content on tablet. Consists of a } \\
\text { random sample of } 17-20 \text { words. }\end{array}$ & $\begin{array}{l}\text { Ethiopia and } \\
\text { South Africa }\end{array}$ \\
\hline $\begin{array}{l}\text { Phonological Awareness and } \\
\text { Literacy Screening (PALS-PreK) [7]. } \\
\text { 1. Letter Identification: Children } \\
\text { name random letters pointed to by } \\
\text { the tester. } \\
\text { 2. Alphabet Recital: Children are } \\
\text { asked to recite the alphabet. } \\
\text { 3. Letter Naming: Children are } \\
\text { asked to name the sound that the } \\
\text { letter represents. } \\
\text { 4. Letter Sounds: Children are } \\
\text { asked to give the sound(s) a letter } \\
\text { makes. } \\
\text { 5. Letter Writing: Children were } \\
\text { asked to write the alphabet from } \\
\text { memory. } \\
\text { Rhyming Tasks: Children are } \\
\text { asked to complete rhyming tasks. }\end{array}$ & $\begin{array}{l}\text { USA } \\
\text { and adapted } \\
\text { versions for } \\
\text { Ethiopia and } \\
\text { South Africa }\end{array}$ \\
\hline $\begin{array}{l}\text { Basic Sight Words } \\
\text { Only children who performed with } \\
80 \% \text { accuracy on vocabulary and } \\
\text { alphabetic tasks were asked to read a } \\
\text { short list of basic sight words that } \\
\text { represented known concepts in apps } \\
\text { (e.g., baby, mother, father, etc.), and a } \\
\text { selection of easily decodable words } \\
\text { (e.g., bat, tap). }\end{array}$ & $\begin{array}{l}\text { Ethiopia and } \\
\text { South Africa }\end{array}$ \\
\hline
\end{tabular}

Table 2: Literacy measures per corresponding study site.

self-organize into learning cells, often of 4-6 children, who explore, play, and discover. Leader and connector roles emerge, where certain children take on the task of sharing discoveries with others. Within this social learning framework, we worked with the communities to ensure children have a place to congregate to play with the tablets together, guided by their own curiosity and each other's.

\section{MEASURES}

Table 2 summarizes literacy measures used for each case study. Their specific purpose was to determine if children were able to acquire pre-literacy skills (e.g., knowledge of sounds \{phonemes\} in words, names of uppercase and lowercase letters) and to expand English vocabulary based on the intervention. 
Correct Vocabulary $(\max =17)$

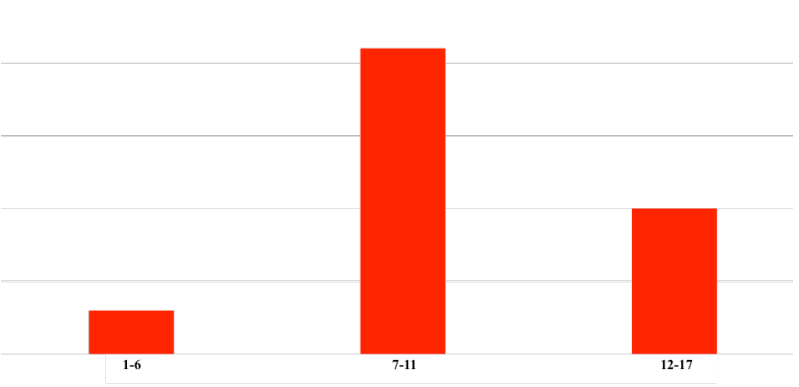

Figure 2: Results from Ethiopia. Number of subjects able to correctly identify vocabulary items.

\section{Engagement Data}

Usage data collected on the tablets were used to assess children's engagement with the intervention as summarized in the description of the platform above. We focus on battery level, app launches, and amount of time spent per app.

\section{OVERVIEW OF PARTICIPANTS AND SITES}

In the following, we present the design, measures and results from three first-of-their-kind studies. Each design mitigates the specific challenges of conducting a rigorous study in these communities. Participants and sites were chosen to explore distinct use cases, representative of under resourced communities:

- Case Study 1: Children in Ethiopia with no access to schools.

- Case Study 2: Children in a South African school with at $50+: 1$ student- teacher ratio.

- Case Study 3: Children at an at-risk, underserved community in the United States.

\section{CASE STUDY 1: ETHIOPIA}

Two villages were chosen as representative of Ethiopia's pastoral populations with no access to schools. The villagers speak a dialect of Oromo and have very rarely heard English or seen written language. There were no appropriate apps or digital activities available in the children's native Oromo language. However, learning to speak and read in English is highly aspirational with improved employment opportunities in the future. Local government and relevant leaders requested an English deployment for these reasons. There was no electricity and no electronic devices in the village. The deployment team provided solar charging equipment and training to village adults. All children in the villages between the approximate ages of 4-11 were given a tablet.

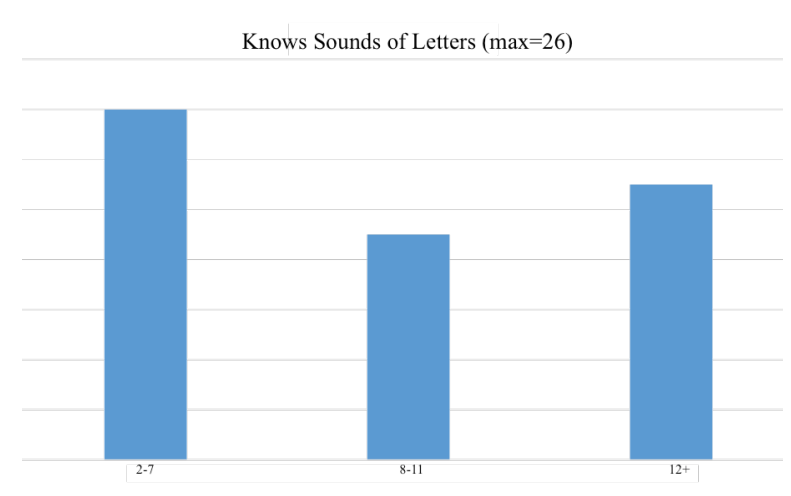

Figure 3: Results from Ethiopia. Number of subjects identifying sounds of letters.

\section{Study Design}

The study design and protocol involved only one condition: every child between the ages of 4-11 years began the study fully illiterate, with no prior exposure to such technology, to school or literate adults. Each child received a tablet $(\mathrm{n}=40$, about 20 tablets in each village). Children freely shared and exchanged tablets over one year, followed by post-testing.

\section{Measures}

In Ethiopia, a member from our US team, our two Ethiopia deployment partners, and a translator administered formal assessments (see Table 2) in both Ethiopian villages at 12 months. Usage data, a measure of engagement, was collected by the tablets.

\section{Literacy Data Results}

Taken as a whole, the literacy assessment and behavioral data document the emergence of literacy in a group of children who have never seen symbolic text, but are motivated to learn.

\section{Vocabulary and Concepts}

See Figure 2. All children knew at least 4 tested English vocabulary words; over half knew more than $50 \%$ of tested words. This result is promising, particularly because tested words were randomly chosen out of many possible words on tablets, and because the children had no environment in which to practice.

\section{Literacy Precursors}

See Figure 3. All children tested knew at least 2 letternames, all but 4 recognized and could name 10 or more English letters in an array, and most importantly, 14 could read a least one of the tested sight words. This group rivaled U.S. Kindergarten-level proficiency. 


\section{Usage Data Results}

Technology Use

All children became "computer-literate" with the tablets. In the first village, all children learned to turn on their tablets within the first day without instruction. In the second village, by the second day all apps were engaged. By the end of the first month every app had been activated with the children totally "at home" with tablets.

\section{Engagement}

Observational data from our deployment team, including videos and photographs, indicate that a dynamic, curiositydriven learning environment emerged in both groups of children. A collaborative atmosphere appeared in which kids of greater ability helped other children by taking a leadership role. Battery and usage data indicate that children used the tablets about 6 hours a day. Usage data from the first village over the year are illustrative. See Figure 3. First, over 325 apps were opened and explored, an example of children's innate curiosity. Second, based on the 20 tablets most used by children, over 85,000 app opening events occurred. Third, peak app use occurred during weeks 3 and 4 with over 9883 apps opened; lowest use occurred during the summer (averaging 405 apps opened during August), potentially related to the local environment. Fourth, children developed favorite apps, with 20 apps accounting for 25 percent of all activities (over 20,000 app opening events), a majority of which were literacy-focused. Thus, as the year progressed, children opened fewer apps, but spent much more time using specific apps, indicating more in-depth engagement with preferred apps over time.

\section{CASE STUDY 2: SOUTH AFRICA}

This study took place in a primary school just outside the

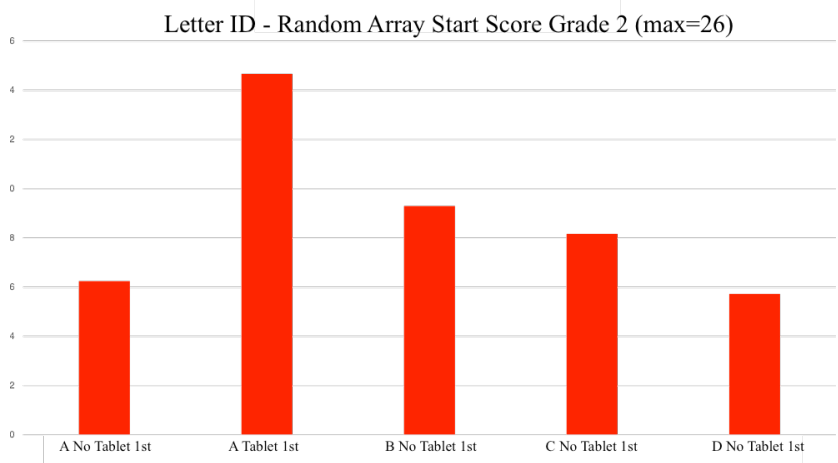

Figure 4: South Africa: Letter Identification at the start of grade 2. Comparing students who had tablets (A Tablet) during previous school year in the 1 st grade for approximately 6-months compared to students who did not have tablets in 1st grade previously.

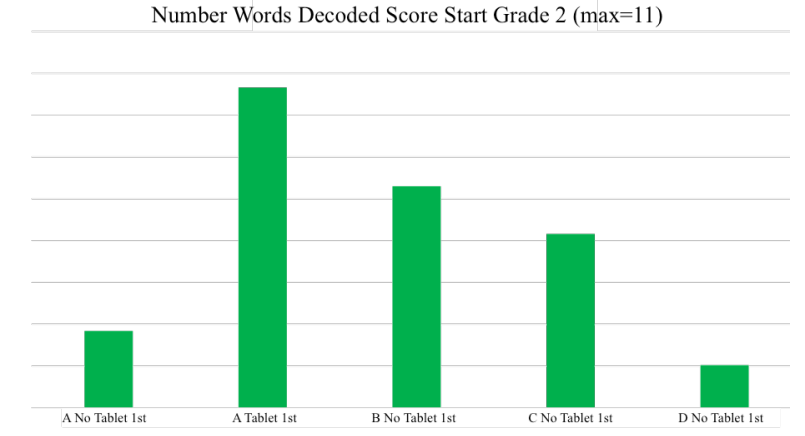

Figure 5: South Africa: Number of Words Decoded at start of grade 2 .

town of KwaDukuza on the north coast of KwaZulu-Natal. The area surrounding the school consists of very poor, informal settlements with low levels of education and high unemployment rates. Electricity and $\mathrm{Wi}-\mathrm{Fi}$ connectivity was available at the school. Participants included children in Reception/ Kindergarten year through Grade 3 (Ages 58).

\section{Study Design}

The initial study design and protocol included one condition: 25-30 tablets were provided to each classroom of children on rotating schedules during a typical school day throughout the week. Class sizes range from 50-99 children per class level. Four Kindergarten level and three 1st grade classes received 3 hours a week of tablet time, while three 2nd grade and three 3rd grade classes received 4 hours a week of tablet time. A total of $n=551$ children participated.

The deployment team was comprised of local educational and technology staff working in conjunction with project staff in the U.S. This initial study took place at one school to evaluate the short-term impact of this model on learning over approximately a 5-month period (August to early December, 2014). Children freely exchanged and shared the tablets with peers throughout class periods, making childspecific data not possible. Rather, class level assessment data was collected on children when the tablets were distributed, and at the start of the next school year.

\section{Measures}

In South Africa, all student testing was completed by local evaluators using literacy measures shown in Table 2. Usage data, as a measure of engagement, was collected by the tablets.

\section{Literacy Data Results}

Children who received the tablets in Grade 1 (Aug 2014) in School A were tested at the start of Grade 2 (Feb 2015) and were compared to Grade 2 children who did not receive tablets from the same school (A) and from other regional schools (B-D). Figures 4 and 5 indicate that children with 


\begin{tabular}{|l|l|l|l|}
\hline Condition & Scenario & Population & Tablet Exposure \\
\hline $\begin{array}{l}\text { Whole Day } \\
\text { Pre-K Class } \\
\text { (WD) } \mathrm{n}=18\end{array}$ & $\begin{array}{l}\text { Traditional all-day Pre-K class staffed } \\
\text { by a teacher and aide. State classroom } \\
\text { curriculum. Pre-testing. }\end{array}$ & $\begin{array}{l}5 \text { children baseline knowledge over 20 } \\
\text { upper case letters. 61\% received } \\
\text { free/reduced cost lunches. 66\% female. }\end{array}$ & $\begin{array}{l}\text { 20 minutes during } \\
\text { class M-F. One night } \\
\text { at home. }\end{array}$ \\
\hline $\begin{array}{l}\text { Half- Day Pre- } \\
\text { K Class (HD) } \\
\mathrm{n}=16\end{array}$ & $\begin{array}{l}\text { Half-day Pre-K class staffed by } \\
\text { teacher. State classroom curriculum. } \\
\text { Pre-testing. }\end{array}$ & $\begin{array}{l}3 \text { children baseline knowledge over 20 } \\
\text { upper case letters. 100\% received } \\
\text { free/reduced cost lunches. 50\% female. }\end{array}$ & $\begin{array}{l}\text { Daily per teacher's } \\
\text { class plan M-F. } \\
\text { Home use M-Th. }\end{array}$ \\
\hline $\begin{array}{l}\text { Off-campus } \\
\text { Virtual Pre-K } \\
\text { (OC) } \\
\mathrm{n}=20\end{array}$ & $\begin{array}{l}\text { No Pre-K class (lottery outcome). } \\
\text { Parents brought children to school } \\
\text { once a week for educational and } \\
\text { support sessions. Pre-testing. }\end{array}$ & $\begin{array}{l}12 \text { children baseline knowledge over 20 } \\
\text { upper case letters. 45\% received } \\
\text { free/reduced cost lunches. 55\% female. }\end{array}$ & $\begin{array}{l}\text { 24/7, full-week } \\
\text { access to tablet at } \\
\text { home. }\end{array}$ \\
\hline $\begin{array}{l}\text { Head Start/ No } \\
\text { Tablet (HS) } \\
\mathrm{n}=12\end{array}$ & $\begin{array}{l}\text { Local Head Start class, staffed by } \\
\text { teacher and aide. State preschool } \\
\text { curriculum. No pre-testing. }\end{array}$ & $\begin{array}{l}100 \% \text { received free/reduced cost lunches. } \\
42 \% \text { female }\end{array}$ & None. \\
\hline $\begin{array}{l}\text { No Pre-K/No } \\
\text { Tablet Group } \\
\text { (NO) } \\
\text { n=68 }\end{array}$ & $\begin{array}{l}\text { Children who did not take part in } \\
\text { school district's Pre-K class or Head } \\
\text { Start. No pre-testing. }\end{array}$ & $\begin{array}{l}100 \% \text { received free/reduced cost lunches. } \\
42 \% \text { female, }\end{array}$ & None. \\
\hline
\end{tabular}

Table 3: Rural US study conditions and descriptions

tablets (A Tablet) had higher scores on letter identification (random array) and words decoded. Not all areas of assessment showed as clear differentiation.

\section{Usage Data Results}

Technology Use

South African children quickly learned to turn on and utilize the tablets, and opened and explored all apps. On average, over 3957 app openings occurred during school days when tablets were available.

\section{Engagement}

During weeks 1-3, the average time spent on an app was $.49, .43 \& .51$ minutes. At the end of the pilot (14-15 weeks later) the average times spent on an app was .82 and .72 minutes. Peak number of apps used occurred during weeks 11-12, with average times .63 and .61 minutes. These results again suggest that children decrease the number of apps opened over time and then become more engaged with a few favorite apps.

\section{CASE STUDY 3: RURAL UNITED STATES}

The US study took place in a rural school district in Alabama (39 people per square mile) with a total elementary student population of 491. Eighty percent of students qualify for free/reduced cost lunch; $40 \%$ are African-American, 58\% Caucasian. The district had limited preschool options and community had small Head Start program. Participants in the study were four years of age before September 2013.

\section{Study Design}

A quasi-experimental, controlled evaluation was performed. There was an inability to completely randomize participants within conditions due to a Pre-K lottery process. The study covers a pilot 4-month deployment. Four conditions were investigated in this case study (Table 3) that represent different levels of traditional Pre-K classroom instruction supplemented with tablet use. Participants were individually assigned a specific tablet (only the school district had access to names for confidentiality purposes). Children in the Off Campus condition (OC) were not enrolled in Pre-K classes, but parents wanted some Pre-k services. This group, therefore, used tablets at home (a virtual Pre-K), and they brought the children to school once a week for parent education and to work with a teacher.

\section{Measures}

Pre-K tablet-condition enrolled children (WD, HD, OC) were assessed on literacy measures in Table 2 in early January 2014 and again at end of school year in April. Further assessment of the 3 experimental (WD, HD, and OC) and the 2 non-tablet comparison groups (HS and NO) were conducted at Kindergarten entry in August 2014.

\section{Literacy Data Results}

This study demonstrates the set of challenges in quasiexperimental designs in schools. Demographic information and literacy measures document the non-random biases in group assignments and small samples $(n=16-20)$. There were significant group differences in percentage of children receiving free and reduced lunches $(\mathrm{OC}=45 \%, \mathrm{WD}=61 \%$, $\mathrm{HD}=100 \%$ ), an index of socioeconomic status, as well as differences in beginning early literacy knowledge (already 


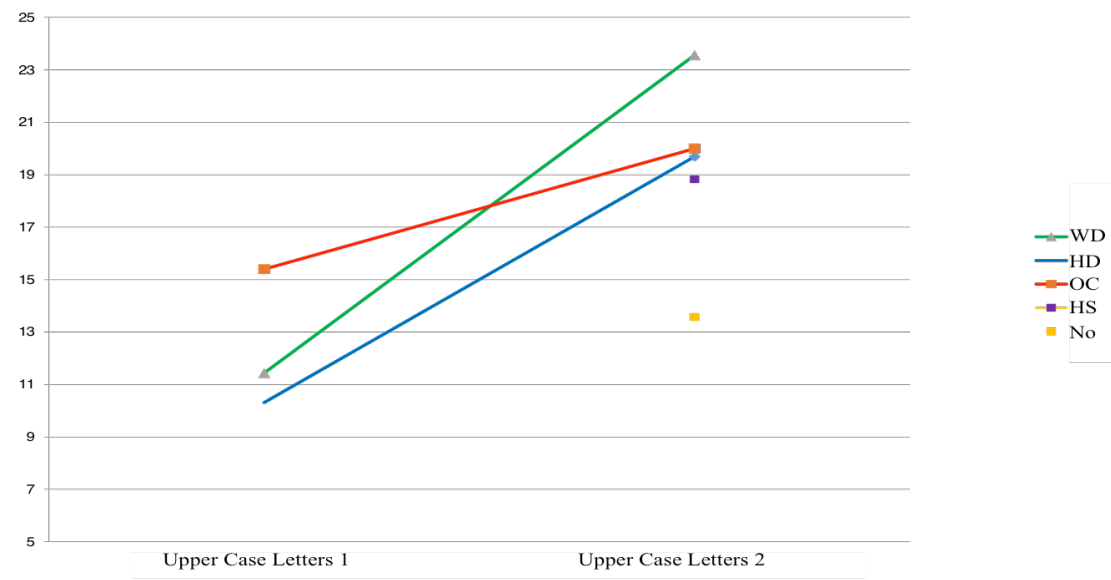

Figure 6: US Deployment. Number of uppercase letters named on PALS-Pre-K (max=26).

knew $16+$ uppercase letters at baseline, $\mathrm{OC}=65 \%$, $\mathrm{WD}=28 \%, \mathrm{HD}=31 \%$ ). These results suggest that the $\mathrm{OC}$ group had significantly higher language and early literacy knowledge at baseline. Such differences, along with the brevity of the study (4-months), make the interpretation of the promising potential of the tablets preliminary.

Within that context, the results of the PALS-Pre-K upper case letter naming evaluation (one of the better predictors of later reading) are of particular interest. Seen in Figure 6, all three tablet-using groups made significant changes in letter naming abilities during this study --- not surprising given that two groups (WD, HD) were placed in preschool classrooms with experienced teachers. Although the WD groups makes the largest gains, the HD group also made significant gains despite much less classroom time. Both groups had large percentages of children now meeting benchmarks of at least 16 letters $(\mathrm{HD}=75 \%, \mathrm{WD}=94 \%)$ compared to baseline. Similar significant changes were found in their ability to provide letter sounds (Figure 7). Interestingly, the HD group made greater gains than the

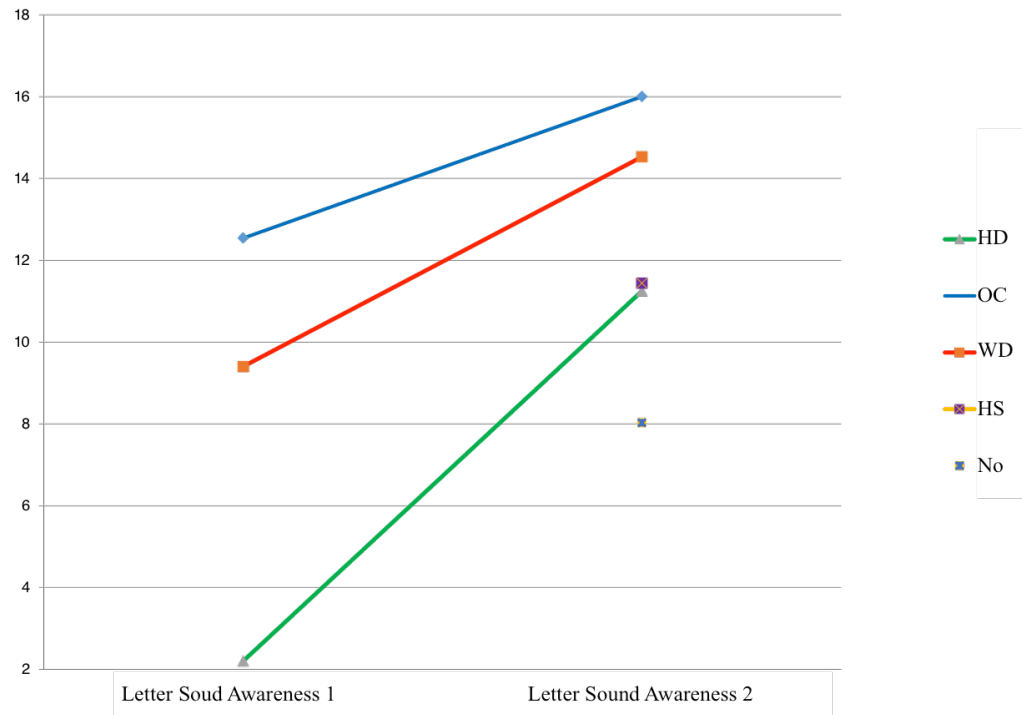


WD class. The amount of change on a receptive vocabulary measure was not significant, although the WD group's change was borderline. This result was expected given the short duration of the study.

None of the children in the HS or NO conditions were given tablets as part of this study. They were comparable to the HD group on socioeconomic status. Neither of these groups had baseline testing, but were tested at entry to Kindergarten like the other children in the tablet study. Their results, shown in each of the figures, indicate the HS group had similar early literacy outcomes as the tablet-use groups, except for significantly lower receptive vocabulary. The NO group showed significantly lower outcomes across all areas evaluated. Such results confirm the welldocumented benefits of quality preschool programs, such as HS, for at-risk children. Without baseline data in the HS and NO groups, it is not possible to make further evaluation of the change that occurred in their abilities.

\section{Usage Data Results}

Technology Use

As in their African counterparts, US children quickly learned to turn on and utilize the tablets, and opened and explored all apps. Over 4000 app openings occurred during those days when school was in session. Peak tablet use occurred around 12-13 weeks post-initiation in the classrooms.

\section{Engagement}

We examined the first four weeks of engagement data across the three tablet-use groups to see how engagement level with tablets might change. In particular, we used "dwell time", the number of seconds a child keeps an app open as a proxy measure of engagement. As mean dwell time increases, children are switching less between apps and more focused on a single app. Repeated-measures ANOVA over the first four weeks for the two preschool (WD, HD) conditions showed dwell time was statistically significantly different across the first four weeks, $F(3,45)=$ $2.95, p=0.04$, partial $\eta 2=0.16$. Duration in WD significantly increased from $146.6 \pm 37.5$ seconds in week 1 , to $177.6 \pm 58.1$ seconds in week 2 , to $184.7 \pm 41.2$ seconds in week 3 to $204.4 \pm 73.3$ seconds, but not HD. We speculate that as children have less time in the HD preschool to use tablets, the teachers prioritized other activities than tablet use. We also examined the difference between use of tablets in the classroom compared to use at home. Since the data has timestamps, we determined when children used the tablets at school or at home. Dwell time was statistically significantly higher when tablets were used at home ( $\mathrm{Mdn}=153.8$ seconds) than in the classroom (Mdn $=138.6$ seconds), $\mathrm{U}=14,332.0, \mathrm{z}=-2.48, \mathrm{p}=0.01$.

An important question is whether this tablet use impacts changes in the early literacy knowledge and outcomes indicated by the post-test scores. The simple index we used is how many apps children opened. Because of the difference in the samples, only the WD and HD groups with their more similar starting abilities and demographics were compared. Also, children who named 16 or more uppercase letters $(25 \%$ of the subjects) were excluded from the analysis because of a concern for ceiling effects on the results.

In Figure 8 there is a systematic relationship $(\mathrm{r}=0.43)$ between number of apps opened and the number of uppercase letters learned over the study period for these

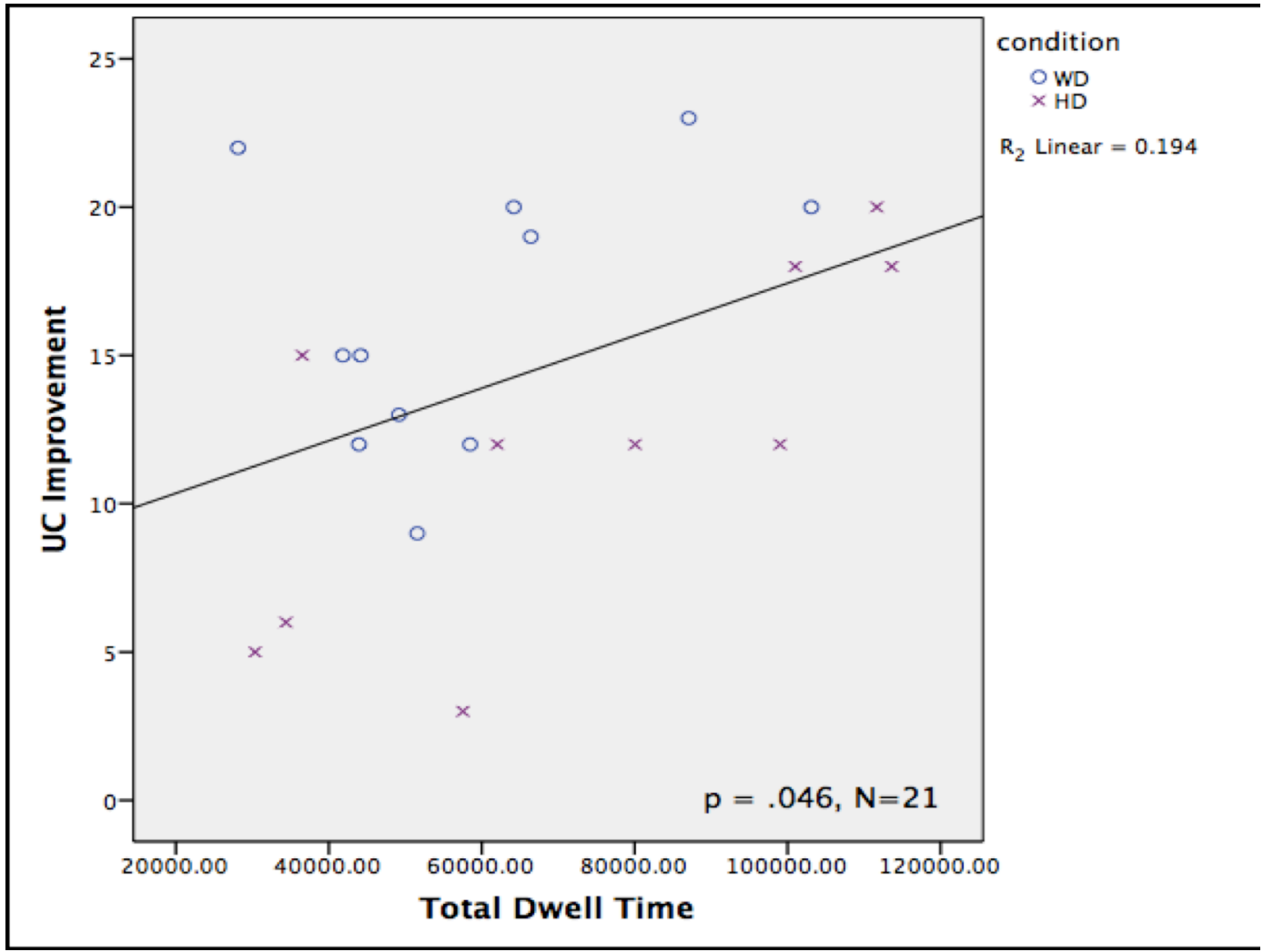

Figure 8: US Deployment. Total dwell time by change in letter naming performance 
groups of children. Such results suggest a potential relationship between tablet use and change in early literacy abilities. Although these results are encouraging, given the limitations of these samples, over-interpretation of their impacts should be avoided.

\section{SUMMARY}

Each of these studies represents a first-of-its kind effort. They provide beginning evidence for the potential of this platform to benefit students across diverse under-resourced educational settings. We are most encouraged that despite challenges faced by each study population (i.e., no access to schools; or schools with 50-100:1 student-teacher ratio in developing countries; or low SES at-risk communities in developed countries), our three independent literacy and vocabulary pilot assessments suggest better performance overall when compared to similar grade students who did not have access to the tablets. We are also realistic about the range of challenges in this work; we believe the lessons learned below pave the way for future developments and advances.

\section{LESSONS LEARNED}

A number of key lessons will have great impact on the success and scalability of future deployments, and these may vary depending on the resources available, the context and location, and the number of children. However some common aspects can be found which greatly influence the outcome of projects. For example, having well-organized and established, on-the-ground deployment partners increases the credibility with community adults and facilitates a productive relationship with the community leaders. Related to this is the importance of building in processes that facilitate informing and eliciting consent from the community members. While initially cumbersome due to the lack of literacy in community members, the need to train facilitators and the necessity of recording responses, we found that formal procedures of consent created buy-in and enthusiasm for what was being offered. We also learned that common assumptions regarding data collection in education technology may be unnecessary. In this project we do not track the identity of individual children on a particular tablet. Not only is a sign-in process almost impossible for pre-literate children, anecdotally we find that unstructured tablet time involves a great deal of tablet exchange which we are hesitant to limit. While still observational, our conclusion so far is that such an environment facilitates a steeper learning curve.

There are a number of different logistical lessons learned that we have begun to capture in a set of deployment "recipes", that can be found along with many other deployment details at wiki.curiouslearning.org.

\section{FUTURE LEARNING AT SCALE}

In the context of this work we have come to believe there are many opportunities for how the technical capabilities, research agenda, and deployments can expand in the future to support learning at scale. Three areas are key: content expansion, peer learning, and technological innovation.

\section{Content Expansion}

There are clear and exciting opportunities for data-driven improvement, and the refinement and expansion of content. Additional apps need to be developed to support literacy beyond the early reading skills focused upon here. Based on our cognitive neuroscience framework, significant content lacunae exist in phonological, semantic, early decoding and blending processes that, when addressed, may propel children's reading acquisition, and ultimately their deepening comprehension abilities. Furthermore, education developers can introduce new content areas to the platform, both to other academic subjects (e.g., STEAM), as well as to provide resources concerning daily life (nutrition, health and hygiene, ethical development).

New apps and new forms of data analysis can help us understand how best to create engaging experiences that can live within both physical and networked virtual social environments to foster learning across deployment sites on a global scale. Our current work has emphasized peer-peer learning among children for a given deployment site. However, there is a compelling opportunity to connect children across sites through the tablets -- where children's curiosity about each other, and their desire to communicate with others across the world can motivate self-expression and sharing through reading and writing.

\section{Understanding Peer Learning}

From a research perspective, a wider range of deployments across even more diverse sites, and the resulting rich and standardized data provided by the platform from each, will make important cross-site and population analyses possible. The platform has already produced a unique cross-cultural data set to establish a data-driven science to understand children's curiosity-driven and peer learning and the efficacy of different content emphases on this. The resulting insights will help communities to better evaluate the critical dimensions that attract these early learners' attention, and engage them over time in tasks that lead to successful learning outcomes. There are also opportunities to develop new literacy and cognitive assessments that can be seamlessly integrated into the tablet experience, either as apps or woven into apps, to supplement traditional pre- and post- testing by trained personnel. Such assessments would generate more longitudinal and finer grained evidencebased assessment of engagement and learning gains. This would not only support evaluating the efficacy of the platform, but would support data-driven improvement of the tablet content and activities.

\section{Technology Innovation}

There are computational science opportunities for machine learning and AI methods to continuously adapt the experience to the needs of any learner anywhere. Capturing longitudinal data on learner's usage and behavioral 
outcomes can be leveraged to build adaptive learning models that scaffold the individual's learning with apps based on their interests and needs, while preserving the learners' ability for choice. Such a model fosters exploration and curiosity for learning, while providing content based on developmental principles.

\section{Growing Community}

The vision of this ongoing project is to support a connected community of contributors for the creation and deployment of educational content to 100 s of millions of learners across many different cultures. To achieve this goal, we will continue to improve the platform to simplify the process of commissioning and distributing tablets. We also seek to empower communities to create and distribute mother-tongue apps and interactive storybooks so that children can learn to read in their home language. By making the device side software (both content management and data collection) open source, we can engage a community of developers to help the system reach as many devices as possible.

\section{ACKNOWLEDGMENTS}

We thank all of our deployment and content partners. We are especially grateful for the support provided by the Italian Development Council, Markos Lemma, Michael Girma, the MRP Foundation, Creesen Naicker, Roanoke County Schools and Dr. David Crouse. We appreciate the generosity of our content partners who donated copies of their software for us to test with our subjects. The children enjoyed them greatly. We would also like to thank Curious Learning (curiouslearning.org), the new nonprofit that is formed to facilitate this approach and to support the platform at scale, as well as provide the platform as a research platform for partners. If you have an interest in becoming a research partner, please contact them. Finally, we are deeply indebted to the children, parents, teachers and communities who participated in these studies.

\section{REFERENCES}

1. Aharony, N., Pan, W., Ip, C., Khayal, I., \& Pentland, (2011). Social fMRI: Investigating and shaping social mechanisms in the real world. Pervasive and Mobile Computing, 7(6), 643-659. http://dx.doi.org/10.1016/j.pmcj.2011.09.004

2. Baron, N. (2014) Words Onscreen: The Fate of Reading in a Digital World. Oxford, New York : Oxford University Press.

3. Bowman, M., Debray, S. K., and Peterson, L. L. 1993. Reasoning about naming systems. ACM Trans. Program. Lang. Syst. 15, 5 (Nov. 1993), 795-825. http://doi.acm.org/10.1145/161468.161471.

4. Chang, A., Breazeal, C., Faridi, F., Roberts, T., Davenport, G., Lieberman, H., Monfort, N. (2012) Textual tinkerability: encouraging storytelling behaviors to foster emergent literacy, Proceedings $\mathrm{CHI}$ '12 Extended Abstracts on Human Factors in Computing Systems, ACM, New York, NY, pp 505520. http://dx.doi.org/10.1145/2212776.2212826

5. Dediu, H. (2014) When will smartphones saturate?

Retrieved October 22, 2015 from http://www.asymco.com/2014/01/07/when-willsmartphones-saturate/

6. Dunn, M., \& Dunn, L. M. (2007). Peabody Picture Vocabulary Test-4. Circle Pines, MN: AGS.

7. Invernizzi, M., Sullivan, A., Meier, J. \& Swank, L. (2004). PALS-PreK technical reference. Richmond, VA: University Printing Services.

8. Kena, G., Musu-Gillette, L., Robinson, J., Wang, X., Rathbun, A., Zhang, J., Wilkinson-Flicker, S., Barmer, A., and Dunlop Velez, E. (2015). The Condition of Education 2015 (NCES 2015-144). U.S. Department of Education, National Center for Education Statistics. Washington, DC. Retrieved October 22, 2015 from http://nces.ed.gov/pubs2015/2015144.pdf.

9. McManis, L. D. (2012). Achieving School Readiness \& Success Using Tablets and Content. Hatch Innovations. https://www.hatchearlylearning.com/?wpfb_dl=8

10. Mitra, S. and Rana, V. (2001) Children and the Internet: Experiments with minimally invasive education in India. The British Journal of Educational Technology, volume 32, issue 2, pp 221-232. http://dx.doi.org/10.1111/1467-8535.00192

11. UNESCO Institute for Statistics. (2014) Government expenditure per student, primary. Retrieved September 1,2015 from

http://data.worldbank.org/indicator/SE.XPD.PRIM.PC. ZS/countries.

12. UNESCO Institute for Statistics. (2013) A Teacher for Every Child: Projecting Global Teacher Needs from 2015-2030. Retrieved September 1, 2015 from http://www.uis.unesco.org/Education/Documents/fs272013-teachers-projections.pdf.

13. Wolf, M. (2007) Proust and the Squid: The Story and Science of the Reading Brain. New York: Harper Collins

14. Wolf, M., \& Gottwald, S. (2015). Android App Survey (Unpublished)

15. Vygotsky, L. (1978). Mind in Society. London: Harvard University Press. 